Rev. Bras. Saúde Prod. Anim., Salvador, v.17, n.3, p.497-507 jul./set., $2016 \quad$ http://www.rbspa.ufba.br ISSN 15199940

\title{
Consumo e digestibilidade de nutrientes em ovinos alimentados com sal forrageiro de faveleira (Cnidoscolus phyllacanthus) ${ }^{1}$
}

\author{
Intake and digestibility of nutrients in sheep fed fodder salt of faveleira ("Cnidoscolus \\ phyllacanthus")
}
OLIVEIRA, Fernanda Melo de ${ }^{2 *}$; OLIVEIRA, Gabriel Jorge Carneiro de ${ }^{3}$; OLIVEIRA, Marcos Lemos Andrade de ${ }^{2}$; JAEGER, Soraya Maria Palma Luz ${ }^{3}$; ALMEIDA, Luiz Henrique Silva ${ }^{3}$; NERY, Igor Bomfim Quadros ${ }^{2}$; LEITE, Laudi Cunha ${ }^{3}$

${ }^{1}$ Parte da dissertação de mestrado do primeiro autor.

${ }^{2}$ Universidade Federal do Recôncavo da Bahia, Programa de Pós-Graduação em Ciência Animal, Cruz das Almas, Bahia, Brasil.

${ }^{3}$ Universidade Federal do Recôncavo da Bahia, Centro de Ciências Agrárias, Ambientais e Biológicas, Cruz das Almas, Bahia, Brasil.

*Endereço para correspondência: nandavet06@yahoo.com.br

\section{RESUMO}

Objetivou-se com este estudo avaliar o consumo e a digestibilidade aparente dos nutrientes em ovinos alimentados com sal forrageiro de faveleira (Cnidoscolus phyllacanthus) com níveis crescentes de cloreto de sódio na sua composição. Foram utilizados 25 carneiros, sem padrão racial definido, não castrados, alocados em baias individuais, distribuídos em um delineamento experimental inteiramente casualizado, com cinco tratamentos e cinco repetições. As dietas que continham 1, 3, 5 e $7 \%$ de cloreto de sódio na composição do sal forrageiro de faveleira foram oferecidas à vontade. Todos os tratamentos receberam feno de capim Tifton-85 moído como dieta basal e água à vontade. As dietas foram oferecidas duas vezes ao dia. Os níveis crescentes de cloreto de sódio no sal forrageiro de faveleira proporcionaram efeito significativo $(\mathrm{P}<0,05)$ sobre o consumo e a digestibilidade aparente da matéria seca, fibra em detergente neutro, proteína bruta, extrato etéreo, carboidratos não-fibrosos e nutrientes digestíveis totais, quando comparados com o tratamento controle. Recomenda-se a inclusão máxima de até $3 \%$ de cloreto de sódio na composição do sal forrageiro de faveleira, por proporcionar aumento no consumo da matéria seca. Todos os níveis testados proporcionaram aumento no consumo de proteína bruta, extrato etéreo e carboidratos nãofibrosos e também melhoraram a digestibilidade aparente de todos os parâmetros avaliados, quando comparados ao tratamento controle, contudo, o nível de $1 \%$ de inclusão de cloreto de sódio na formulação do sal forrageiro de faveleira apresentou melhor digestibilidade.

Palavras-chave: caatinga, ovinocultura, pequenos ruminantes, suplementação

\section{SUMMARY}

This study evaluated the intake and apparent digestibility of nutrients by sheep fed with fodder salt with faveleira (Cnidoscolus phyllacanthus), with increasing levels of sodium chloride in the preparation. Twenty five sheep, mongrel, not castrated, placed in individual cages, and distributed in a completely randomized design with five treatments and five replicates. Diets were offered the will containing 1, 3, 5 and $7 \%$ sodium chloride in the fodder salt. All animals also received grounded Tifton- 85 hay (Cynodon sp) as basal diet abundant, and water abundant. All Diets were offered twice a day. Increasing levels of sodium chloride no fodder salt faveleira provided differences $(\mathrm{P}<0.05)$ on intake and apparent digestibility of dry matter, neutral detergent fiber, crude protein, ether extract, total digestible nutrients and non-fibrous carbohydrates, when compared to the control treatment. It is recommended maximum to include up to $3 \%$ of sodium chloride in the 
composition of forage salt faveleira, for providing improved intake of dry matter. All tested levels provided improvement inteke of crude protein, ether extract, and non-fiber carbohydrates and also improved the apparent digestibility of all parameters when compared to the control treatment, however, the level of $1 \%$ inclusion of sodium chloride in the fodder salt faveleira showed better digestibility.

Keywords: caatinga, sheep, small ruminants, supplementation

\section{INTRODUÇÃO}

A ovinocultura é uma das mais importantes atividades econômica e social da região Nordeste brasileira (NOGUEIRA et al., 2011). Contudo, o sistema de produção predominante e o extensivo, no qual na maioria dos casos não permite a obtenção de índices zootécnicos adequados, necessitando de estratégias que possam trazer melhorias nutricionais aos rebanhos (VOLTOLINI et al., 2011).

Dada a estacionalidade na produção forrageira nos trópicos, fica explícita a necessidade de fontes externas de nutrientes que garantam o desempenho animal ao longo do ano, trazendo sustentabilidade ao sistema (HOFFMANN et al., 2014). Nesse contexto, justificam-se estudos de formas alternativas de suplementação (FERREIRA et al., 2012). No entanto, as principais fontes suplementares são de alto custo, sendo necessário o estudo de fontes alimentares alternativas que possam apresentar boa relação custo/benefício (IRINO et al., 2011).

O sal forrageiro (SF) é uma tecnologia de suplementação, definida como uma mistura de feno de eudicotiledôneas nativas ou exóticas que contenha um alto percentual de proteína, com sal mineral (OLIVEIRA et al., 2010). Todavia, há a necessidade de mais estudos acerca da qualificação da forrageira utilizada na confecção dessa tecnologia, notadamente quanto ao consumo e sua digestibilidade. $\mathrm{O}$ consumo voluntário de forragem é o principal fator ligado a produtividade (ELOY et al., 2014), e para Van Soest (1994), a digestibilidade é a descrição qualitativa do percentual de consumo do alimento, e serve para qualificar os alimentos quanto ao seu valor nutritivo.

A faveleira [Cnidoscolus phyllacanthus (Muell. Arg.) Pax et K. Hoffman], planta nativa da caatinga, pertencente à família das Euforbiáceas, é uma árvore tipicamente xerófila (DRUMOND et al., 2007). É uma espécie muito importante para o desenvolvimento da região semiárida, em virtude de seus múltiplos usos, alta disseminação e completa adaptação as condições adversas dessa região (CAVALCANTI et al., 2012). Porém, segundo Drumond et al. (2007), informações sobre digestibilidade e valor nutritivo da faveleira são escassas. Este estudo teve por objetivo determinar o melhor nível de inclusão de cloreto de sódio $(\mathrm{NaCl})$ na composição do sal forrageiro de faveleira, através do consumo e digestibilidade aparente dos componentes das dietas fornecidas a ovinos sem padrão racial definido (SPRD).

\section{MATERIAL E MÉTODOS}

O trabalho foi conduzido no município de Campo Formoso, localizado no norte da Bahia, que apresenta um clima Semiárido Tropical. Foi desenvolvido sob aprovação da Comissão de Ética no Uso de Animais (CEUA) da Universidade Federal do Recôncavo da Bahia (UFRB). O experimento teve duração de 16 dias, sendo 10 dias de adaptação e 6 dias de coleta de dados, 
em setembro de 2014. Foram utilizados 25 animais da espécie ovina, sem padrão racial definido (SPRD), machos, com aproximadamente 300 dias de idade, peso corporal médio de $40 \mathrm{~kg} \pm 3,32$, alojados em baias individuais de $1 \mathrm{~m}^{2}$, providas de comedouro, bebedouro e saleiro. Os animais foram distribuídos em um delineamento experimental inteiramente casualizado (DIC), com cinco tratamentos e cinco repetições.

Os tratamentos foram constituídos de sais forrageiros de faveleira com 1, 3, 5 e $7 \%$ de cloreto de sódio $(\mathrm{NaCl})$. As proporções dos ingredientes em cada tratamento estão representadas na Tabela 1. $\mathrm{O} \mathrm{NaCl}$ utilizado na confecção do sal forrageiro estava contido em uma mistura mineral comercial.

Tabela 1. Ingredientes dos tratamentos e suas proporções

\begin{tabular}{cccc}
\hline Tratamentos & Sal Mineral* $(\mathrm{g})$ & Feno de Faveleira $(\mathrm{g})$ & $\mathrm{NaCl}(\%)$ \\
\hline T0 & ad libitum & 0 & 0 \\
T1 & 25 & 975 & 1 \\
T2 & 70 & 930 & 3 \\
T3 & 115 & 885 & 5 \\
T4 & 150 & 850 & 7 \\
\hline
\end{tabular}

*Níveis de garantia por Kg: cálcio $90 \mathrm{~g}$, cloro $240 \mathrm{~g}$, cobalto $35 \mathrm{mg}$, cobre $150 \mathrm{mg}$, enxofre $10 \mathrm{~g}$, ferro $1.300 \mathrm{mg}$, fósforo $45 \mathrm{~g}$, iodo $40 \mathrm{mg}$, magnésio $8 \mathrm{~g}$, manganês $2.300 \mathrm{mg}$, selênio $15 \mathrm{mg}$, sódio $156 \mathrm{~g}$, zinco $2800 \mathrm{mg}$ e flúor $450 \mathrm{mg}$.

As folhas da faveleira foram coletadas com o auxílio de uma luva contra agentes escoriantes, a fim de evitar o contato direto da pele com os espinhos urticantes encontrados nessa planta. Em seguida, as folhas foram expostas ao sol e viradas periodicamente durante três dias para a confecção do feno.

$\mathrm{Na}$ formulação do sal forrageiro, o feno de faveleira foi moído, utilizando peneiras com crivos de $5 \mathrm{~mm}$ de diâmetro, com o intuito de evitar a seletividade pelos animais e também para facilitar a homogeneização da mistura com o sal mineral. Todos os animais receberam feno de Tifton-85 (Cynodon spp.), como suporte básico alimentar, com baixo teor proteico para simular condição de pastejo em período de seca. As dietas, contendo o sal forrageiro e o feno de Tifton-85, foram fornecidas à vontade em duas refeições diárias, às 7:00 e às 17:00 horas, que foram ajustadas conforme o consumo dos animais, de modo a permitir uma sobra de $10 \%$.

As sobras diárias de sal forrageiro, sal mineral e feno de Tifton-85, foram recolhidas, pesadas e subtraídas do total fornecido, a fim de quantificar $o$ alimento consumido pelos animais, individualmente.

Do $11^{\circ}$ ao $16^{\circ}$ dias do período experimental, foram coletadas fezes dos animais, diretamente na porção final do reto, para determinação dos coeficientes de digestibilidade aparente da matéria seca (MS), fibra em detergente neutro $(\mathrm{FDN})$, proteína bruta (PB), extrato etéreo (EE) e carboidratos não-fibrosos (CNF), seguindo a seguinte distribuição: $1^{\circ}$ dia $(18: 00 \mathrm{~h}), 2^{\circ}$ dia $(10: 00 \mathrm{~h}), 3^{\circ}$ dia (12:00h), $4^{\circ}$ dia (14:00h), $5^{\circ}$ dia (16:00h) e $6^{\circ}$ dia $(8: 00 \mathrm{~h})$, antes de oferecer a dieta do período seguinte (FERREIRA et al., 2009). As amostras de fezes foram armazenadas em freezer, numa temperatura de $-10^{\circ} \mathrm{C}$. 
Rev. Bras. Saúde Prod. Anim., Salvador, v.17, n.3, p.497-507 jul./set., $2016 \quad \underline{\text { http://www.rbspa.ufba.br }}$

Foram coletadas amostras dos alimentos e sobras de todos os animais diariamente. O material coletado foi processado em amostras compostas de cada animal por tratamento, para serem submetidas a análises bromatológicas no Laboratório de Nutrição Animal da UFRB. A composição químico-bromatológica dos ingredientes utilizados na dieta experimental, está demonstrada na Tabela 2.

Tabela 2. Composição químico-bromatológica dos ingredientes utilizados na dieta experimental (\% MS)

\begin{tabular}{lcrcccc}
\hline \multirow{2}{*}{ Frações bromatológicas } & \multirow{2}{*}{$\begin{array}{c}\text { Feno de } \\
\text { Tifton-85 }\end{array}$} & \multirow{2}{*}{$\begin{array}{c}\text { Feno de } \\
\text { Faveleira }\end{array}$} & \multicolumn{4}{c}{ Níveis de inclusão de NaCl no SF de } \\
\cline { 5 - 7 } & & & \multicolumn{4}{c}{ Faveleira } \\
\hline MS & 80,74 & 84,76 & 82,64 & 78,83 & 75,01 & 72,05 \\
MM & 12,38 & 21,64 & 21,10 & 20,13 & 19,15 & 18,39 \\
PB & 5,44 & 14,95 & 14,57 & 13,90 & 13,23 & 12,71 \\
EE & 1,12 & 6,90 & 6,73 & 6,42 & 6,11 & 5,90 \\
CT & 81,06 & 56,51 & 55,10 & 52,55 & 50,01 & 48,03 \\
CNF & 2,03 & 22,88 & 22,31 & 21,28 & 20,25 & 19,45 \\
CEL & 32,55 & 16,07 & 15,67 & 14,95 & 14,22 & 13,66 \\
HEM & 28,37 & 5,14 & 5,00 & 4,77 & 4,55 & 4,37 \\
FDNcp & 79,03 & 33,63 & 32,78 & 31,27 & 29,76 & 28,59 \\
FDA & 50,66 & 28,49 & 27,78 & 26,50 & 25,21 & 24,22 \\
LIG & 18,11 & 12,42 & 12,11 & 11,55 & 10,99 & 10,56 \\
NDT & 49,13 & 72,63 & 70,95 & 69,76 & 69,01 & 68,73 \\
\hline
\end{tabular}

Matéria seca (MS), matéria mineral (MM), proteína bruta (PB), extrato etéreo (EE), carboidratos totais (CT), carboidratos não-fibrosos (CNF), celulose (CEL), hemicelulose (HEM), fibra em detergente neutro corrigida para cinzas e proteína (FDNcp), fibra em detergente ácido (FDA), lignina (LIG) e nutrientes digestíveis totais estimado (NDT estimado, segundo NRC, 1985).

A estimativa da produção fecal foi realizada utilizando-se a fibra em detergente neutro indigestível (FDNi) como indicador interno. As amostras de fezes, alimentos e sobras foram incubadas in situ no rúmen bovino, utilizando-se sacos de TNT com metragem de $5 \mathrm{~cm}^{2}$, por um período de 264 horas (CASALI et al., 2008). A quantidade da amostra incubada foi de $20 \mathrm{mg} \mathrm{MS} / \mathrm{cm}^{2}$ para alimentos, sobras e fezes. O material remanescente da incubação foi colocado em estufa para retirada da umidade, pesados e posteriormente submetido à extração com detergente neutro, e o resíduo considerado FDNi (MERTENS, 2002).
Para as análises bromatológicas, as amostras diárias de cada animal foram processadas em estufa de ar forçado a $65^{\circ} \mathrm{C}$, por 72 horas. As determinações químicas de matéria seca (MS), matéria mineral (MM), proteína bruta (PB) e extrato etéreo (EE) foram realizadas conforme metodologias descritas no AOAC (1990). A fibra em detergente neutro (FDN) e ácido (FDA), celulose, hemicelulose e lignina, conforme Van Soest et al. (1991). O teor de fibra em detergente neutro corrigido para cinzas e proteína (FDNcp) foi estimado segundo recomendações Licitra et al. (1996) e Mertens (2002). O teor de carboidratos totais (CT) foi calculado conforme Sniffen et al. (1992), onde: 
Rev. Bras. Saúde Prod. Anim., Salvador, v.17, n.3, p.497-507 jul./set., $2016 \quad \underline{\text { http://www.rbspa.ufba.br }}$

$\mathrm{CT}(\%)=100-(\% \mathrm{~PB}+\% \mathrm{EE}+$ $\% \mathrm{MM})$. O teor de carboidratos não fibrosos (CNF) foi calculado conforme Weiss (1999), onde: CNF (\%) $=100-$ $(\% \mathrm{FDNcp}+\% \mathrm{~PB}+\% \mathrm{EE}+\% \mathrm{MM})$.

O teor de NDT observado foi calculado utilizando a seguinte fórmula: NDT = $\mathrm{PBd}+\mathrm{CNFd}+\mathrm{FDNcpd}+(\mathrm{EEd} \times 2,25)$ sendo PBd, CNFd, FDNcpd e EEd correspondentes a: proteína bruta digestível, carboidratos não fibrosos digestíveis, fibra em detergente neutro corrigida para cinza e proteína digestível e extrato etéreo digestível, respectivamente, sendo o extrato etéreo multiplicado por 2,25 devido esta fração conter, aproximadamente, o dobro de energia do que as demais (WEISS, 1999).

O cálculo de consumo e coeficientes de digestibilidade dos nutrientes do feno de capim Tifton-85 e do sal forrageiro de faveleira foram realizados segundo Schneider \& Flatt (1975).

Os dados obtidos foram submetidos à análise de variância segundo o modelo estatístico do delineamento inteiramente casualizado. Foi aplicado o teste de Dunnett a $5 \%$ de probabilidade para comparação das médias dos tratamentos com níveis de $\mathrm{NaCl}$ em relação ao tratamento controle. Para as médias dos tratamentos com níveis de $\mathrm{NaCl}$ foi ajustada equações de regressão polinomial. As análises foram realizadas com auxílio do software SISVAR (FERREIRA, 2011).

\section{RESULTADOS E DISCUSSÃO}

A inclusão de $\mathrm{NaCl}$ no sal forrageiro de faveleira, influenciou significativamente $(\mathrm{P}<0,05)$ o consumo de matéria seca (CMS), fibra em detergente neutro $(\mathrm{CFDN})$, proteína bruta (CPB), extrato etéreo (CEE) e carboidratos nãofibrosos (CCNF), como pode ser observado na Tabela 3.

Tabela 3. Consumos de nutrientes na dieta total e respectivos coeficientes de variação

\begin{tabular}{lccccccc}
\hline \multirow{2}{*}{ Item } & \multicolumn{3}{c}{ Níveis de NaCl no SF de faveleira (\%) } & \multicolumn{2}{c}{$\begin{array}{c}\text { Equações de } \\
\text { regressão / } \mathrm{R}^{2} \%\end{array}$} & $\mathrm{CV} \%$ \\
\cline { 2 - 6 } & 0 & 1 & 3 & 5 & 7 & 1 & 2,00 \\
$\mathrm{CMS}^{1}$ & 1379,28 & $1646,05^{*}$ & $1592,61^{*}$ & 1406,96 & $1249,11^{*}$ & 2 & 10,05 \\
$\mathrm{CFDN}^{1}$ & 1081,13 & $987,12^{*}$ & $962,48^{*}$ & $907,87^{*}$ & $827,42^{*}$ & 3 & 11,13 \\
$\mathrm{CFDN}^{2}$ & 78,38 & $59,97^{*}$ & $60,43^{*}$ & $64,53^{*}$ & $66,24^{*}$ & 3,13 \\
$\mathrm{CPB}^{1}$ & 53,65 & $151,99^{*}$ & $137,14^{*}$ & $101,73^{*}$ & $85,38^{*}$ & 4 & 5,23 \\
$\mathrm{CPB}^{2}$ & 3,89 & $9,23^{*}$ & $8,61^{*}$ & $7,23^{*}$ & $6,84^{*}$ & 5 & 6,97 \\
$\mathrm{CEE}^{1}$ & 10,46 & $54,79^{*}$ & $49,28^{*}$ & $36,19^{*}$ & $23,53^{*}$ & 6 & 7 \\
$\mathrm{CEE}^{2}$ & 0,76 & $3,33^{*}$ & $3,09^{*}$ & $2,57^{*}$ & $1,88^{*}$ & 8,78 \\
$\mathrm{CCNF}^{1}$ & 32,32 & $172,23^{*}$ & $149,00^{*}$ & $100,03^{*}$ & $68,66^{*}$ & 8 & 5,27 \\
$\mathrm{CCNF}^{2}$ & 2,34 & $10,46^{*}$ & $9,36^{*}$ & $7,11^{*}$ & $5,50^{*}$ & 9 & 7,21 \\
\hline
\end{tabular}

*Significativo a $5 \%$ de probabilidade pelo teste de Dunnett.

${ }^{1}=\mathrm{g} / \mathrm{dia} ;{ }^{2}=\%$ na matéria seca.

Consumos de: $\mathrm{CMS}=$ matéria seca, $\mathrm{CFDN}=$ fibra em detergente neutro, $\mathrm{CPB}=$ proteína bruta, $\mathrm{CEE}=$ extrato etéreo e $\mathrm{CCNF}=$ carboidratos não-fibrosos.

${ }^{1} \hat{y}=-68,824 x+1749 / R^{2}=95,94 ;{ }^{2} \hat{y}=-26,686 x+1028 / R^{2}=94,81 ;{ }^{3} \hat{y}=1,1455 x+58,211 / R^{2}=92,24$ ${ }^{4} \hat{y}=-11,762 x+166,11 / R^{2}=97,22 ;{ }^{5} \hat{y}=-0,4275 x+9,6875 / R^{2}=95,65 ;{ }^{6} \hat{y}=-5,3435 x+62,322 / R^{2}=$ 97,$28 ;{ }^{7} \hat{y}=-0,2435 x+3,6915 / R^{2}=95,86 ;{ }^{8} \hat{y}=-17,984 x+194,42 / R^{2}=98,32 ;{ }^{9} \hat{y}=-0,8565 x+$ $11,534 / \mathrm{R}^{2}=98,49$. 
Rev. Bras. Saúde Prod. Anim., Salvador, v.17, n.3, p.497-507 jul./set., $2016 \quad \underline{\text { http://www.rbspa.ufba.br }}$

O valor médio do CMS encontrado dentre os tratamentos em que houve suplementação foi de $1473,68 \mathrm{~g} / \mathrm{dia}$, valor próximo àquele preconizado pelo NRC (2007), que é em torno de 1,6kg MS por dia $\left(40 \mathrm{~g} \mathrm{~kg}^{-1} \mathrm{dia}^{-1}\right)$, para ovinos com peso corporal médio de $40 \mathrm{~kg}$. Pessoa et al. (2013), afirmam que resultados de consumo de MS superiores a 3,0\% do peso corporal em ovinos podem ser considerados satisfatórios por proporcionar ingestão adequada de nutrientes quando em dietas corretamente balanceadas.

Os resultados observados nos tratamentos com 1 e $3 \%$ de $\mathrm{NaCl}$ no sal forrageiro (SF) de faveleira evidenciou o aumento do consumo da MS na dieta total (Tabela 3), não havendo diferença estatística entre ambos os tratamentos. Este resultado pode estar relacionado principalmente ao maior consumo de PB nesses tratamentos, ocasionado pelo maior percentual de feno de faveleira na dieta, que permitiu uma maior eficiência da fermentação microbiana ruminal, promovendo assim um maior aproveitamento do FDN e esvaziamento ruminal, que por sua vez estimulou o consumo (BERCHIELLI et al., 2006).

O menor consumo de matéria seca observado nos animais estudados foi no tratamento com nível de $7 \%$ de inclusão de $\mathrm{NaCl}$ na composição do sal forrageiro de faveleira, que pode estar associado ao maior nível de inclusão desse composto químico. Segundo Paulino (2000), a maior inclusão de $\mathrm{NaCl}$ proporciona um efeito auto-regulador do consumo voluntário pelos animais.

Verificou-se um baixo valor do CMS no tratamento em os animais que foram alimentados exclusivamente com Feno de Tifton-85 (Tabela 3). Esse resultado pode ser atribuído ao maior teor de FDN na dieta, pois segundo Mertens (1992), o consumo de matéria seca é correlacionado negativamente com a concentração de FDN.

O CFDN na matéria seca, nos tratamentos em que os animais foram suplementados com SF de faveleira (Tabela 3), está de acordo com os sistemas nutricionais mais recentes como o Cornell Net Carbohydrate and Protein System (CNCPS) para ovinos (CANNAS, 2004), que estabelecem exigências mínimas de FDN nas dietas entre 20 e $24,5 \%$, abaixo dos quais a fermentação e a síntese de proteína microbiana ruminal seriam influenciados negativamente.

O CPB na matéria seca, no tratamento com maior inclusão de $\mathrm{NaCl}$, apresentouse abaixo de 7\% (Tabela 3). Sengundo Van Soest (1994), para garantir adequada fermentação dos carboidratos estruturais no rúmen, e assegurar o crescimento da microbiota ruminal, a dieta deve conter um mínimo de 7\% de PB. Mehrez \& Orskov (1977), dizem que teores abaixo deste afeta o consumo de matéria seca, restringe a ingestão voluntária e, consequentemente, o consumo de energia pelo comprometimento da função ruminal, decrescendo a eficiência de utilização do alimento.

Para o CEE na matéria seca, os valores encontrados (Tabela 3 ) estão de acordo com a afirmação de Palmquist \& Mattos (2006), que preconizam que o teor de extrato etéreo na dieta atinja o nível máximo de $5 \%$ do valor total, uma vez que, a partir deste nível, os lipídeos podem afetar negativamente o consumo de nutrientes, seja por mecanismos regulatórios, que controlam o consumo de alimentos, seja pela capacidade limitada dos ruminantes de oxidar os ácidos graxos.

$\mathrm{O}$ maior CCNF nos tratamentos em que os animais foram suplementados com SF de faveleira (Tabela 3), pode ser justificado pela inclusão da faveleira na dieta, que proporcionou um incremento de CNF na dieta total. Segundo Menezes 
Rev. Bras. Saúde Prod. Anim., Salvador, v.17, n.3, p.497-507 jul./set., $2016 \quad \underline{\text { http://www.rbspa.ufba.br }}$

et al. (2006), esse fato também pode ser explicado pela necessidade dos microrganismos em fazer grupamentos carbonados doados pelos carboidratos não-fibrosos, a fim de sintetizar suas proteínas. Dessa forma houve maior degradação dessa fração do alimento e uma consequente elevação do consumo.

Houve diferença significativa $(\mathrm{P}<0,05)$ para a digestibilidade aparente da MS
(DMS), fibra em detergente neutro (DFDN), proteína bruta (DPB), extrato etéreo (DEE), nutrientes digestíveis totais (DNDT) e carboidratos nãofibrosos (DCNF) nos tratamentos que tiveram uma inclusão crescente de $\mathrm{NaCl}$ na formulação do sal forrageiro de faveleira, quando comparados com $\mathrm{o}$ tratamento controle (Tabela 4).

Tabela 4. Digestibilidade aparente dos nutrientes na dieta total

\begin{tabular}{lccccccc}
\hline \multirow{2}{*}{ Item } & \multicolumn{4}{c}{ Níveis de NaCl no SF de faveleira (\%) } & \multicolumn{2}{c}{$\begin{array}{c}\text { Equações de } \\
\text { regressão / R }\end{array}$} & CV \% \\
\cline { 2 - 7 } & 0 & 1 & 3 & 5 & 7 & 1 & 3,92 \\
\hline DMS (\%) & 56,08 & $66,47^{*}$ & $64,52^{*}$ & $62,83^{*}$ & $61,44^{*}$ & & 1 \\
DFDN (\%) & 55,33 & $78,59^{*}$ & $77,81^{*}$ & $76,48^{*}$ & $75,99^{*}$ & 2 & 3,51 \\
DPB (\%) & 52,76 & $86,85^{*}$ & $84,07^{*}$ & $83,02^{*}$ & $82,88^{*}$ & 3 & 5,94 \\
DEE (\%) & 50,27 & $76,37^{*}$ & $73,75^{*}$ & $73,52^{*}$ & $72,95^{*}$ & 4 & 4,09 \\
NDT (\%MS) & 51,03 & $72,21^{*}$ & $68,89^{*}$ & $65,55^{*}$ & $62,96^{*}$ & 5 & 7,21 \\
DCNF (\%) & 54,59 & $63,94^{*}$ & $60,50^{*}$ & $59,43 *$ & $55,97^{*}$ & 6 & 4,90 \\
\hline
\end{tabular}

*Significativo a $5 \%$ de probabilidade pelo teste de Dunnett.

Digestibilidade de: DMS = matéria seca, $\mathrm{DFDN}=$ fibra em detergente neutro, $\mathrm{DPB}=$ proteína bruta, $\mathrm{DEE}=$ extrato etéreo, $\mathrm{NDT}=$ nutrientes digestíveis totais e $\mathrm{DCNF}=$ carboidratos não-fibrosos

${ }^{1} \hat{y}=-0,84 x+67,17 / R^{2}=99,45 ;{ }^{2} \hat{y}=-0,46 x+79,05 / R^{2}=97,31 ;{ }^{3} \hat{y}=0,17 x^{2}-1,97 x+88,62 / R^{2}=99,66 ;$ ${ }^{4} \hat{y}=0,13 x^{2}-1,55 x+77.66 / R^{2}=94,56 ;{ }^{5} \hat{y}=-0.46 x+79.05 / R^{2}=97,31 ;{ }^{6} \hat{y}=-1,25 x+64,96 / R^{2}=96,48$.

Os percentuais encontrados para a DMS nos tratamentos onde os animais foram suplementados com SF de faveleira (Tabela 4), está de acordo com Souto \& Aronovich (2002), que afirmam que a digestibilidade aparente da matéria seca só influi na ingestão de alimento até o nível de $67 \%$, quando a digestibilidade está acima desse valor, diminui o consumo de forragem por parte do animal.

Resultado semelhante para a DMS foi observado por Pereira et al. (2012), que avaliaram a digestibilidade aparente in vivo do feno de faveleira na alimentação de ovinos como dieta exclusiva, e encontraram o valor de 63,66\%. Drumond et al. (2007) e Lima (1996) avaliando a digestibilidade aparente in vitro da MS da parte aérea desta eudicotiledônea encontraram os valores $65,47 \%$ e $62,42 \%$, respectivamente.

A DMS foi menor para a dieta exclusiva à base de feno de Tifton-85, devido ao maior teor de FDN presente nessa forragem. Esse resultado comprova que esta fração da dieta apresenta menor digestibilidade aparente que os demais componentes do alimento, fato explicado por Norton (1984), que afirma que para o ruminante o conteúdo celular da planta apresenta geralmente maior digestibilidade que as frações da parede celular.

O maior percentual para DMS nos tratamentos que tiveram inclusão do SF de faveleira, se deve ao incremento de PB proporcionado por essa Euforbiácea. Segundo Mertens \& Rotz (1989), o aumento da concentração dos 
constituintes não-fibrosos na dieta, com o incremento da suplementação, faz com que haja uma rápida disponibilidade dos nutrientes no trato gastrintestinal dos ruminantes, favorecendo a digestibilidade.

No trabalho, os tratamentos em que os animais foram alimentados com dois ingredientes (feno de Tifton-85 e sal forrageiro de faveleira com diferentes níveis de inclusão de $\mathrm{NaCl}$ ), a percentagem média para DFDN foi de $77,22 \%$. Em contrapartida Pereira et al. (2012), ao avaliarem a digestibilidade aparente da faveleira, onde foram utilizadas apenas folhas e caules tenros cujas plantas se encontravam em estágio de floração, com 41,92\% de FDN, encontraram $57,32 \%$ para a digestibilidade dessa fração do alimento. Fato explicado por Grant (1997), que afirma que a rápida taxa de passagem ruminal do alimento com baixo teor de FDN é o principal fator que explica a baixa digestibilidade de sua fração fibrosa. Logo, em dietas com alta quantidade de fibra há um aumento da consistência ruminal maximizando a digestão dessa fração do alimento.

Os percentuais para DPB nos tratamentos em que houve suplementação com sal SF de faveleira, confeccionado com as folhas dessa Euforbiácea, foram superiores ao tratamento controle. Esse resultado pode ser justificado pela qualidade digestiva da PB existente no feno das folhas da faveleira, e também pelo alto teor dessa fração do alimento nessa forrageira, em relação ao feno de Tifton-85. Segundo Cameron et al. (1991), a digestibilidade da PB aumenta com o teor de PB do alimento. Van Soest (1994), também comenta que a digestibilidade é influenciada diretamente pelo consumo de alimentos e composição do alimento na dieta.

Nos tratamentos em que os animais foram suplementados com SF de faveleira, confeccionado com feno das folhas dessa forrageira, os percentuais encontrados para a DEE foram superiores ao tratamento controle (Tabela 4), fato atribuído ao maior consumo dessa fração do alimento (EE) proporcionado pela inclusão da faveleira na dieta. Segundo Van Soest (1994), a maior concentração deste componente nos suplementos, incrementa sua participação na dieta total, reduzindo a participação relativa da fração metabólica fecal. Segundo Palmquist (1989), a vantagem da utilização de lipídios na alimentação animal deve-se ao incremento da densidade calórica da dieta, em razão de seu elevado valor energético (aproximadamente $6 \mathrm{Mcal} \mathrm{El} / \mathrm{kg} \mathrm{MS}$ ), que pode ser explorada de várias maneiras, além de permitir aumento no consumo de energia.

Os valores de NDT também foram expressivos nos tratamentos em que os animais foram suplementados com SF de faveleira, provavelmente em virtude do aumento no consumo de EE, resultando maior densidade energética nas dietas.

Maiores percentuais para DCNF observados nos tratamentos em que os animais foram suplementados com SF de faveleira, podem estar associados aos maiores teores dessa fração do alimento na dieta, em relação ao tratamento controle. Segundo Van Soest (1994), os CNF são de fácil fermentação, assim, disponibilizam maior aporte de energia para o crescimento dos microrganismos ruminais e permitem maior adesão em menor tempo de colonização e, consequentemente, maior digestão do alimento.

Com base nos resultados encontrados, recomenda-se a inclusão máxima de até $3 \%$ de $\mathrm{NaCl}$ na composição do sal forrageiro de faveleira, por proporcionar aumento no consumo da matéria seca. Todos os níveis testados proporcionaram aumento no consumo de proteína bruta, 
Rev. Bras. Saúde Prod. Anim., Salvador, v.17, n.3, p.497-507 jul./set., $2016 \quad \underline{\text { http://www.rbspa.ufba.br }}$ ISSN 15199940

extrato etéreo e carboidratos não-fibrosos e também melhoraram a digestibilidade aparente de todos os parâmetros avaliados, quando comparados ao tratamento controle. Contudo, o nível de $1 \%$ de inclusão de cloreto de sódio na formulação do sal forrageiro de faveleira apresentou melhor digestibilidade.

\section{REFERÊNCIAS}

\section{ASSOCIATION OF OFFICIAL AGRICULTURAL CHEMISTS - AOAC. Official Methods of the association of the agricultural chemists. 15.ed. Washington, 1990. \\ BERCHIELLI, T.T.; RODRIGUEZ, N.M.; OSÓRIO NETO, E. Nutrição de ruminantes. Jaboticabal: Funep, 2006, $583 p$.}

CAMERON, M.R.; KLUSMEYER, T.H.; LYNCH, G.L. Effects of urea and starch on rumen fermentation, nutrient passage to the duodenum, and performance of cows. Journal of Dairy Science, v.74, p.1321-1336, 1991.

CANNAS, A. A Feeding of lactating ewes. In: PULINA, G. (Ed.). Dairy sheep feeding and nutrition. Bologna: Avenue Media, 2004. p.123-166.

CASALI, A.O.; DETMANN, E.; VALADARES FILHO, S.C. Influência do tempo de incubação e do tamanho de partículas sobre os teores de compostos indigestíveis em alimentos e fezes bovinas obtidos por procedimentos in situ. Revista Brasileira de Zootecnia, v.37, p.335-342, 2008.

CAVALCANTI, M.T.; BORA, P.S.; CARVAJAL, J.C.L. Análise térmica e perfil de ácidos graxos do óleo das amêndoas de faveleira (Cnidosculus phyllacanthus Pax. \& K. Hoffm) com e sem espinho. Revista Verde, v.7, p.154-162, 2012.

DRUMOND, M.A.; SALVIANO, L.M.C.; CAVALCANTI, N.B.

Produção, distribuição da biomassa e composição bromatológica da parte aérea da faveleira. Revista Brasileira de Ciência Agrária, v.2, p.308-310, 2007.

ELOY, L.R.; ROCHA, M.G.; PÖTTER, L. Consumo de forragem por novilhas de corte recebendo farelo de arroz com e sem ionóforo. Ciência Rural, v.44, p.1223-1228, 2014.

FERREIRA, D.J.; LANA, R.P.; ZANINE, A.M. Ingestão e digestibilidade aparente em ovinos alimentados com silagens de capimelefante inoculadas com Streptococcus bovis. Arquivo Brasileiro de Medicina Veterinária e Zootecnia, v.64, p.397402, 2012.

FERREIRA, D.F. Sisvar: a computer statistical analysis system. Ciência \& Agrotecnologia, v.35, p.1039-1042, 2011.

\section{FERREIRA, M.A.; VALADERES} FILHO, S.C.; MARCONDES, M.I. Avaliação de indicadores em estudos com ruminantes: digestibilidade.

Revista Brasileira de Zootecnia, v.38, p.1568-1573, 2009.

GRANT, R.J. Interactions among forages and nonforages fiber sources. Journal of Dairy Science, v.80, p.1438, 1997.

HOFFMANN, A.; MORAES, E.H.B.K.; MOUSQUER, C.J. Produção de bovinos de corte no sistema de pastosuplemento no período seco. Nativa, v.2, p.119-130, 2014. 
Rev. Bras. Saúde Prod. Anim., Salvador, v.17, n.3, p.497-507 jul./set., $2016 \quad \underline{\text { http://www.rbspa.ufba.br }}$ ISSN 15199940

IRINO, M.M.X.; FATURI, C.; VASCONCELOS, H.G.R.

Digestibilidade aparente em ovinos alimentados com farelo de coco na Amazônia Oriental. Revista de Ciências Agrárias, v.54, p.131-136, 2011.

LICITRA, G.; HERNANDEZ, T.M.; VAN SOEST, P.J. Standardization of procedures for nitrogen fracionation of ruminant feed. Animal Feed Science Technological, v.57, p.347-358, 1996.

LIMA, J.L.S. Plantas forrageiras das caatingas, usos e potencialidades. Petrolina, EMBRAPA CPATSA/PNE/RBG-KEW, 1996. 24p.

MEHREZ, A.Z.; ORSKOV, E.R. A study of the artficial fibre bag technique for determining the digestibility of feeds in the rumen. Journal of Agricultural Science, v.88, p.645-650, 1977.

MENEZES, D.R.; ARAÚJO, G.G.L.; SOCORRO, E.P. Consumo de nutrientes em dietas contendo resíduo desidratado de uva de vitivinícolas associado à palma forrageira "in natura" e diferentes níveis de uréia para ovinos. In: REUNIÃO ANUAL DA SOCIEDADE BRASILEIRA DE ZOOTECNIA, 43, 2006, João Pessoa, PB. Anais... João Pessoa, PB: SBZ, 2006.

MERTENS, D.R. Analysis of fiber in feeds and its use in feed evaluation and ration formulation. In: SIMPÓSIO INTERNACIONAL DE RUMINANTES, 1992, Lavras. Anais... Lavras: SBZ, 1992. p.1-33.

MERTENS, D.R. Gravimetric determination of amylase-treated neutral detergent fiber in feeds with refluxing in beakers or crucibles: collaborative study. Journal of AOAC International, v.85, p.1217-1240, 2002.
MERTENS, D.R.; ROTZ, C.A.

Functions to descrinbing changes. In: Dairy cow characteristics during lactation for use. in DAFOSYM. U.S. Madison, WI: Dairy Forage Research Center Research Summaries, 1989. p.114.

NATIONAL RESEARCH COUNCIL NRC. Nutrient requirements of domestic animals: Nutrient requirements of sheep, 6 ed. Washington: National Academy of Science, 1985. 112p.

NATIONAL RESEARCH COUNCIL NRC. Nutrient requirements of small ruminants. Washington, D.C.: National Academy Press, 2007, p.362.

NOGUEIRA, D.M.; MISTURA, C.; TURCO, S.H.N. Aspectos clínicos, parasitológicos e produtivos de ovinos mantidos em pastagem de capim-aruana irrigado e adubado com diferentes doses de nitrogênio. Animal Sciences, v.33, p.175-181, 2011.

NORTON, B.W. Differences between species in forage quality. In: HACKER, J. B. (Ed.). Nutritional limits to animal production from pastures. Santa Lucia, Queensland: Farnham Royal, 1984. p.89-110.

OLIVEIRA, G.J.C.; JAEGER, S.M.P.L.; BAGALDO, A.R. Fodder salt fed to small ruminants. Revista Brasileira de Zootecnia, v.39, p.364368, 2010.

PALMQUIST, D.L.; MATTOS, W.R.S. Metabolismo de lipídeos. In: BERCHIELLI, T. T.; PIRES, A. V.; OLIVEIRA, S.G. (Ed.). Nutrição de ruminantes. Jaboticabal: FUNEP, 2006, p.287-310. 
Rev. Bras. Saúde Prod. Anim., Salvador, v.17, n.3, p.497-507 jul./set., $2016 \quad \underline{\text { http://www.rbspa.ufba.br }}$ ISSN 15199940

PALMQUIST, D.L. Suplementação de lipídeos para vacas em lactação. In: SIMPÓSIO SOBRE PRODUÇÃO ANIMAL, 1989, Piracicaba. Anais... Piracicaba: Fundação de Estudos Agrários Luiz de Queiroz, 1989. p.1125.

PAULINO, M.F. Suplementação de bovinos em pastejo. Informe Agropecuário, v.21, p.96-106, 2000.

PEREIRA, V.L.A.; ALVES, A.L.A.; SILVA, V.M. Valor nutritivo e consumo voluntário do feno de faveleira fornecido a ovinos no semiárido pernambucano. Revista Caatinga, v.25, p.96-101, 2012.

PESSOA, R.A.S.; FERREIRA, M.A.; SILVA, F.M. Diferentes suplementos associados à palma forrageira em dietas para ovinos: consumo, digestibilidade aparente e parâmetros ruminais. Revista Brasileira de Saúde e Produção Animal [online], v.14, p.508-517, 2013.

SCHNEIDER, B.H.; FLATT, W.P. The evaluation of feeds through digestibility experiments. Georgia: University of Georgia Press, 1975. 423p.

SNIFFEN, C.J.; O'CONNOR, J.D.; VAN SOEST, P.J. A net carbohydrate and protein system for evaluating cattle diets. II. Carbohydrate and protein availability. Journal of Animal Science, v.70, p.3562-3577, 1992.

SOUTO, S.M.; ARONOVICH, S. Sombreamento em forrageiras aspectos agronômicos $\mathbf{e}$ microbiologicos. CNPBS: EMBRAPA, 2002. 43p. (Documentos, 10).

VAN SOEST, P.J. Nutritional ecology of the ruminant. 2.ed. Ithaca: Cornell University Press, 1994. 476 p.
VAN SOEST, P.J.; ROBERTSON, J.B.; LEWIS, B.A. Methods for dietary fiber, neutral detergent fiber, and nostarch polyssacharides in relation to animal nutrition. Journal of Dairy Science, v.74, p.3583-3597, 1991.

VOLTOLINI, T.V.; MORAES, S.A.; ARAUJO, G.G.L. Concentrate levels for lambs grazing on buffel grass.

Revista Ciência Agronômica, v.42, p.216-222, 2011.

WEISS, W.P. Energy prediction equations for ruminant feeds. In: CORNELL NUTRITION CONFERENCE FOR FEED MANUFACTURERS, 61. 1999, Ithaca. Proceedings... Ithaca: Cornell University, 1999. p.176-185.

Data de recebimento: 16/12/2015

Data de aprovação: 21/07/2016 